\title{
PRÁTICAS AVALIATIVAS EM EDUCAÇÃO FÍSICA NOS ANOS INICIAIS DA EDUCAÇÃO BÁSICA
}

\author{
Antonio Evanildo Cardoso de Medeiros Filho ${ }^{1}$ \\ Kaio Breno Belizário de Oliveira² \\ Geórgia Antonia Gomes Maciel Forte ${ }^{3}$ \\ Pelegrino Santos Verçosa ${ }^{4}$ \\ Jose Airton de Freitas Pontes Junior ${ }^{5}$
}

\begin{abstract}
RESUMO: A avaliação causa inquietação nos variados públicos integrantes da comunidade escolar. Nesse sentido, o estudo teve como objetivos: a) analisar como a avaliação na Educação Física no Ensino Infantil e Fundamental I vem sendo abordada nas publicações científicas, via revisão integrativa e b) verificar as práticas de avaliação no Ensino Infantil e Fundamental I na percepção de docentes de Educação Física de acordo com o sexo e tipo de escola. A amostra foi constituída por 23 professores, de escolas públicas e/ou particulares da capital do Ceará, Fortaleza. As principais evidências foram: a) escassez de estudos sobre a avaliação em Educação Física no Ensino Infantil e Fundamental I, b) as produções científicas acerca das práticas avaliativas na Educação Física têm demonstrado críticas aos processos metodológicos e técnicos acometidos pelo professores e, c) a realização de avaliação formativa ou processual é mais frequente por parte dos professores de escola particulares.
\end{abstract}

Palavras-chave: Educação física. Crianças. Avaliação educacional.

\section{ASSESSMENT PRACTICES IN PHYSICAL EDUCATION IN THE INITIAL YEARS OF BASIC EDUCATION}

ABSTRACT: The use of evaluation causes some uneasiness in the various public members of the school community. This way, the present study aimed to focus on these objectives: a) to analyze how evaluation in Physical Education in Pre-school

\footnotetext{
${ }^{1}$ Graduado em Educação Física. Mestrando em Educação na Universidade Federal do Ceará (UFC)- Benfica. Bolsista da Fundação Cearense de Apoio ao desenvolvimento Científico e Tecnológico (FUNCAP). FortalezaCE/Brasil. e-mail: evanildofilho17@gmail.com

${ }^{2}$ Graduado em Educação Física. Mestrando em Educação na Universidade Federal do Ceará (UFC)- Benfica. Bolsista da Coordenação de Aperfeiçoamento de Pessoal de Nível Superior (CAPES). Fortaleza-CE/Brasil. e-mail: kaiobelizario12@gmail.com

${ }^{3}$ Graduada em Pedagogia. Professora da Educação Infantil no Colégio Santa Cecília. Fortaleza-CE/Brasil. e-mail: georgiaantonia@hotmail.com

${ }^{4}$ Doutor em Educação. Professor da Universidade Federal do Acre (UFAC)-Rio Branco-AC/Brasil. e-mail: peleacre@yahoo.com.br

${ }^{5}$ Doutor em Educação. Docente da Universidade Estadual do Ceará (UECE) vinculado ao curso de Educação Física, ao Mestrado Profissional Ensino na Saúde (CMEPES) e ao Programa de Pós-Graduação em Educação (PPGE). Itaperi. Fortaleza-CE/Brasil. e-mail: japontesjr@gmail.com
} 
education and Elementary School has been approached in scientific publications, through an integrative revision and b) to verify the evaluation practices in the perception of Physical Education teachers, according to gender and type of school. The sample consisted of 23 teachers, working in public and / or private schools in Fortaleza-CE. The main evidences were: a) lack of studies about evaluation, b) the scientific productions about the evaluative practices in Physical Education have demonstrated some criticisms to the methodological and technical processes undertaken by the teachers and, c) the performance of formative or procedural evaluation is more frequent by private school teachers.

Keywords: Physical education. Children. Educational assessment.

\section{PRÁCTICAS EVALUATIVAS EN EDUCACIÓN FÍSICA EN LOS AÑOS INICIALES DE LA EDUCACIÓN BÁSICA}

RESUMEN: E La evaluación causa inquietud en los variados públicos integrantes de la comunidad escolar. De ese modo, el estudio tuvo como objetivos: a) analizar cómo la evaluación en Educación Física en la Enseñanza Infantil y Fundamental I es abordada en las publicaciones científicas, vía revisión integrativa y b) verificar las prácticas de evaluación en la percepción de docentes de Educación Física de acuerdo con el sexo y tipo de escuela. La muestra fue constituida por 23 profesores, de escuelas públicas y / o particulares de la capital de Ceará, Fortaleza. Las principales evidencias fueron: a) escasez de estudios sobre la evaluación, b) las producciones científicas acerca de las prácticas evaluativas en la Educación Física han demostrado críticas a los procesos metodológicos y técnicos acometidos por los profesores $y, c)$ la realización de evaluación formativa o procesal es más frecuente por parte de los profesores de escuelas particulares.

Palabras clave: Educación física. Niños. Evaluación educacional.

\section{Introdução}

A avaliação causa inquietação nos variados públicos integrantes da comunidade escolar - professor, alunos, gestores e outros - no mesmo instante que é instrumento fundamental para desenvolver a qualidade da educação e do ensino (BAUER; GATTI; TAVARES, 2013; BERTOLIN; MARCON, 2015). Nesse sentido, a avaliação pode se posicionar por via de soluções de problemas, sendo base para potencializar mudanças sociais via políticas educacionais, ou seja, tendo como objetivo coletar informações que permitam excelentes tomadas de decisões (VIANNA, 1993; CALDERÓN; BORGES, 2013). 
Diante disso, a avaliação educacional contempla diferentes campos de atuação sendo, algumas delas: avaliação de sala de aula ou avaliação do ensino-aprendizado; avaliação institucional; avaliação de programas e avaliação de currículo. Dessa forma, dependendo em que campo pretende-se avaliar será necessário delinear métodos específicos e necessários para alcançar resultados significativos (FREITAS et al., 2017). Dentre as dimensões apresentadas, este trabalho tem como foco a avaliação do processo de ensino-aprendizagem ou "avaliação de sala de aula".

O referido campo busca acompanhar os alunos durante o processo de ensinoaprendizagem. Assim, permite detectar "falhas", bem como solucioná-las logo em seguida, ou seja, possibilita a reconfiguração do processo de ensino-aprendizagem. Sabendo disso, fica notória a sua relevância nas atividades escolares quando se pretende atingir os resultados esperados na aprendizagem dos educandos.

Contudo, o uso de instrumento de coleta de informações dos professores se restringe, muitas vezes, em provas. Além disso, os resultados registrados em forma de notas - conotação numérica - ou conceito - conotação verbal - se limitam em certos casos ao processo de verificação, ou seja, nenhuma intervenção pedagógica é efetivada visando à reestruturação do processo de ensino-aprendizagem (NOVAES; FERREIRA; MELLO, 2014). Para tanto, alertase que as provas não devem ser o único instrumento de coleta de informações a ser utilizadas pelos professores em suas práticas avaliativas.

Nesse contexto, é preciso que o professor, durante o processo avaliativo, se coloque como um ser instigado a perceber os níveis de aprendizagem dos alunos em relação aos objetivos de ensino. Essa atitude caracteriza o professor pesquisador, na medida em que este faz delineamentos, identifica e busca suporte nas avaliações para formular estratégias metodológicas em um viés de melhoria da sua prática de ensino, e ainda, como meio de constante diagnóstico dos os níveis de aprendizagem dos educandos (PONTES JUNIOR, 2014).

No que se refere à Educação Física escolar, os objetivos pedagógicos e avaliativos se reconfiguraram de acordo com o contexto social e educativo de cada época, assim como apresentam as denominadas tendências pedagógicas, respectivamente: Higienista, Militarista, Tecnicista, Popular e Pedagógica. É importante mencionar que nas três primeiras 
tendências priorizavam-se as capacidades físicas como aspectos avaliativos. Já as duas últimas passam a considerar também os aspectos cognitivos e sociais (PONTES JUNIOR, 2012).

No cenário contemporâneo dessa disciplina na Educação Básica, o processo avaliativo compreende tanto a dimensão motora, quanto cognitiva e social frente a um processo formativo, assim como rege a Lei de Diretrizes e Bases da Educação Nacional - $n^{\circ}$ 9394/96 (BRASIL, 1996). Dessa forma, compreende-se o processo formativo da avaliação mediante as seguintes etapas: a) Diagnóstica, realizada no início de alguma ação com a intenção de identificar conhecimentos prévios adquiridos pelos alunos em outros contextos, b) Processo, realizada durante o processo formativo possibilitando medidas corretivas e c) Somativa, realizada ao final de algum processo, formativo ou não, na intenção de identificar se os objetivos de aprendizagem foram alcançados (VIANNA, 2000; CALLADO; ARANDA; LÓPEZPASTOR, 2014).

Nessa perspectiva, considerando a importância e complexidade das práticas avaliativas no processo de ensino aprendizagem, as quais também são orientadas por meio de documentos norteadores como os Parâmetros Curriculares Nacionais para Educação Física (BRASIL, 1997, 1998) e a terceira versão da Base Nacional Comum Curricular (BRASIL, 2017), esta pesquisa pretende investigar as práticas avaliativas na Educação Física no Ensino Infantil e Fundamental I. Para tanto foram delineados dois objetivos: a) analisar como a avaliação na Educação Física no Ensino Infantil e Fundamental I vem sendo abordada nas publicações científicas, via revisão integrativa e b) verificar as práticas de avaliação no Ensino Infantil e Fundamental I na percepção de docentes de Educação Física de acordo com o sexo e tipo de escola.

\section{Método}

No primeiro momento, ao objetivar analisar como a avaliação na Educação Física no Ensino Infantil e Fundamental I vem sendo abordada nas publicações científicas, foi realizada uma revisão integrativa. Os procedimentos metodológicos realizados foram os seguintes: de início, é importante explicitar que para seleção dos estudos foram percorridas as respectivas etapas, com base nos passos metodológicos sugeridos por Galvão, Pansani e Harrad (2015): i) "estabelecimento de hipótese ou questão de pesquisa"; ii) "amostragem ou busca na 
A. E. C. De Medeiros Filho e K. B. B. de Oliveira e G. A. G. M. Forte e P. S. VERÇOSA E J. A. DE F. PONTES JUNIOR

literatura"; iii) "avaliação dos estudos incluídos na revisão"; iv) "interpretação dos resultados" e v) "síntese do conhecimento ou apresentação da revisão".

Foram selecionados artigos completos publicados em revistas/periódicos, teses de doutorado e dissertações de mestrado publicados nos últimos 5 (cinco) anos (2013 a 2017). A delimitação desse período se justifica a partir das orientações propostas por Galvan (2017) que sugere um delineamento dos últimos 5 ou 7 anos. A partir disso, optou-se pela primeira alternativa por representar a data da última revisão de literatura sistematizada com a temática semelhante realizada por Novaes, Ferreira e Mello (2014) em que objetivaram caracterizar as produções científicas acerca da avaliação na Educação Física escolar nos três níveis de ensino: Ensino Infantil, Fundamental e Médio.

Sendo assim, foi delimitado o início de buscas de produções científicas publicadas no ano seguinte, ou seja, a partir de 2013, e os seguintes descritores com operadores booleanos "and" e "or": Educação Infantil; Educação Física; Avaliação do ensino aprendizagem; Ensino Fundamental; Avaliação formativa, e nas seguintes bases de dados eletrônicas: Scientific Electronic Library Online (SciELO), Sistema Regional de Información en Línea para Revistas Científicas de América Latina (Latindex), Education Resources Information Centere (ERIC), Google Acadêmico e Biblioteca Digital de Teses e Dissertações (BDTD). Os referidos portais de trabalhos acadêmicos são classificados na área de educação pela Coordenação de Aperfeiçoamento de Pessoal de Nível Superior (CAPES).

Como critério de exclusão optou-se por excluir estudos publicados fora do período mínimo estabelecido (antes de 2013), bem como qualquer tipo de revisão, como, por exemplo, revisão bibliográfica, integrativa, sistemática e metanálise. No segundo momento, ao se propor identificar quais são as práticas de avaliação no Ensino Infantil e Fundamental I na percepção de docentes de Educação Física, de acordo com o sexo e tipo de escola, foi elaborado um estudo de natureza quantitativa, descritivo e transversal (THOMAS; NELSON; SILVERMAN, 2012).

\section{Participantes}

A amostra foi composta por 23 professores (as) de Educação Física, atuando em escolas públicas e/ou particulares da capital do Ceará, Fortaleza. A maioria dos participantes foi do 
sexo feminino $(56,5 \%)$ e de escolas públicas $(52,2 \%)$, dos quais foram selecionados de acordo com o exercício da docência no Ensino Infantil e Fundamental I, tanto professores efetivos a partir de concurso público, bem como admitidos por contrato temporário, conhecido também como Admissão em Caráter temporário (ACT).

\section{Procedimentos e instrumentos de coleta}

Para coleta dos dados foi utilizado o questionário desenvolvido e validado por Pontes Junior (2012), o qual tem como objetivo avaliar as práticas avaliativas em Educação Física escolar. Na análise da consistência dos itens nesta coleta foi obtido $\alpha=0,71$ no teste do Alfa de Cronbach. Os dados foram analisados por meio de distribuição relativa (percentual) e para isto foi utilizado o programa SPSS versão 22.0.

\section{Aspectos éticos}

A participação da amostra se deu de forma voluntária, sendo esclarecido para os participantes que as informações coletadas seriam utilizadas somente para fins de pesquisa.

Além disso, o estudo atendeu a Resolução no 510, de 07 de abril de 2016, do Conselho Nacional de Saúde referente à "Não serão registradas nem avaliadas pelo sistema CEP/CONEP: I - pesquisa de opinião pública com participantes não identificados", pois se trata de um estudo de opinião sobre o nível de concordância dos docentes e sem identificação dos participantes.

\section{Resultados}

\section{Revisão integrativa}

Realizada as buscas em pares nas bases de dados, foram selecionados, considerando o título, 36 artigos completos e 35 trabalhos na qualidade de dissertação ou tese. Desses, foram excluídos 24 artigos completos e 20 dissertações e teses após a leitura do resumo. Em seguida, após a identificação do ano de publicação, foram excluídos 07 artigos completos e 11 entre dissertações e teses. 
A. E. C. de Medeiros Filho e K. B. B. de Oliveira e G. A. G. M. Forte e P. S. VERÇOSA E J. A. DE F. PONTES JUNIOR

Por último, após a leitura na íntegra foram selecionados somente 03 artigos completos e 03 dissertações e teses para análise e discussão, conforme mostra a Figura 1.

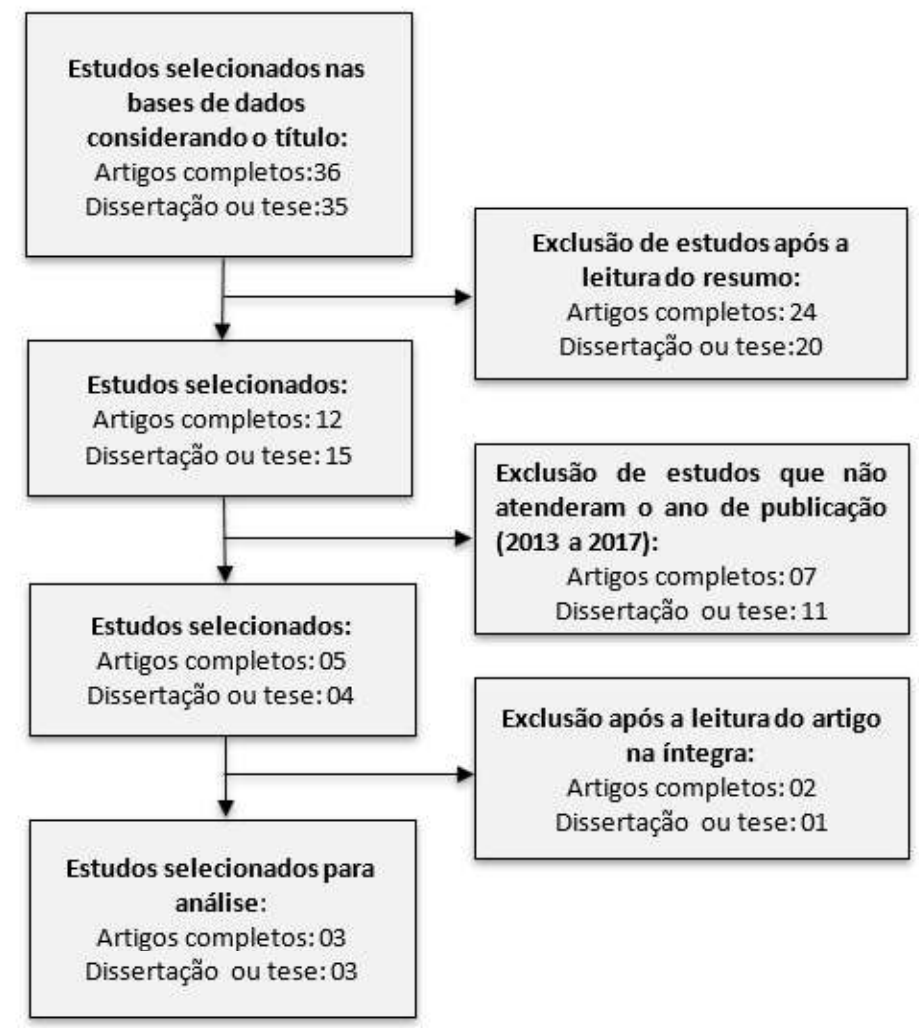

Figura 1 - Fluxograma percorrido para seleção das produções científicas Fonte: Elaborada pelos autores.

Na Figura 1 podem ser observadas as produções científicas selecionadas na revisão integrativa. Nota-se poucos estudos sobre a avaliação em Educação Física escolar no Ensino Infantil e Fundamental I no recorte temporal estabelecido, uma vez que, considerando os critérios de exclusão foram selecionados apenas 6 estudos ( 3 artigos completos; 2 teses de doutorado e 1 dissertação de mestrado). Embora não selecionado, vale ressaltar que foi desconsiderada a revisão de literatura sistematizada de Novaes, Ferreira e Mello (2014). No Quadro 1 podem ser observadas as principais críticas à avaliação e os principais resultados dos estudos selecionados.

Percebe-se nos estudos selecionados a importância que os pesquisadores têm aplicado às práticas avaliativas em Educação Física escolar. Tal importância pode estar 
relacionada à relevância das práticas avaliativas no processo de ensino-aprendizagem e aos próprios resultados de suas investigações, os quais têm demostrado uma desvalorização do ato de avaliar nesse componente curricular.

Quadro 1 - Críticas à avaliação e os principais resultados das produções científicas selecionadas.

\begin{tabular}{|c|c|c|}
\hline Autor/ano & Principais críticas à avaliação & Principais resultados do estudo \\
\hline Colasanto (2014) & $\begin{array}{l}\text { A coordenação pedagógica, } \\
\text { diante certos relatórios de avaliação } \\
\text { realizados pelo professor, se sentia } \\
\text { impossibilitada para aprimorar a a } \\
\text { prática pedagógica do professor. }\end{array}$ & $\begin{array}{l}\text { Constata-se que a opinião da } \\
\text { criança pode trazer à prática } \\
\text { docente importantes elementos } \\
\text { para o replanejamento/ } \\
\text { reestruturação das atividades. }\end{array}$ \\
\hline Matsumoto (2014) & $\begin{array}{l}\text { Os procedimentos e os } \\
\text { instrumentos de registro utilizados } \\
\text { para realizar o acompanhamento } \\
\text { das crianças precisam ser variados, } \\
\text { e condizentes com os objetivos da } \\
\text { avaliação na Ensino Infantil. }\end{array}$ & $\begin{array}{l}\text { A avaliação não permite } \\
\text { sabermos o que realmente passa } \\
\text { pela cabeça do aluno. Dessa } \\
\text { forma é preciso procurar sentido } \\
\text { nas reproduçães e testar esses } \\
\text { sentidos em diferentes formas e } \\
\text { contextos. }\end{array}$ \\
\hline Wagner e Francine \\
(2013)
\end{tabular}

Fonte: Elaborado pelos autores.

No Quadro 2 estão dispostas as características metodológicas das produções científicas selecionadas. Dessa forma, nota-se que se trata de trabalho de caráter descritivo, de abordagem qualitativa e desenvolvido em apenas um período de tempo, ou seja, de recorte 
A. E. C. de Medeiros Filho e K. B. B. de Oliveira e G. A. G. M. Forte e P. S. VERÇOSA E J. A. DE F. PONTES JUNIOR

temporal. No Quadro 2, também podem ser observadas características das amostras utilizadas nesses estudos.

Quadro 2 - Aspectos metodológicos das pesquisas selecionadas.

\begin{tabular}{|c|c|c|}
\hline Autor/ano & Amostra & Tipo de estudo \\
\hline $\begin{array}{l}\text { Colasanto (2014) } \\
\text { Ed. Infantil }\end{array}$ & $\begin{array}{l}\text { Duas Escolas Municipais de Educação } \\
\text { Infantil - EMEls, do município de São } \\
\text { Paulo, que recebem crianças de } 3,4 \text { e } 5 \\
\text { anos de idade }\end{array}$ & $\begin{array}{l}\text { Estudo descritivo, de } \\
\text { abordagem qualitativa, } \\
\text { documental e transversal }\end{array}$ \\
\hline $\begin{array}{l}\text { Matsumoto (2014) } \\
\text { Ed. Infantil }\end{array}$ & $\begin{array}{l}4 \text { professoras e um Professor de educação } \\
\text { física da rede pública de ensino do Estado } \\
\text { de São Paulo }\end{array}$ & $\begin{array}{l}\text { Estudo descritivo, de } \\
\text { abordagem qualitativa, } \\
\text { exploratório e transversal }\end{array}$ \\
\hline $\begin{array}{l}\text { Wagner e Francine } \\
\qquad \begin{array}{l}\text { (2013) } \\
\text { Ensino } \\
\text { Fundamental I }\end{array}\end{array}$ & $\begin{array}{l}3 \text { professoras de Educação Física das } \\
\text { séries iniciais do Ensino Fundamental }\end{array}$ & $\begin{array}{l}\text { Estudo descritivo, de } \\
\text { abordagem qualitativa, } \\
\text { exploratório e transversal }\end{array}$ \\
\hline $\begin{array}{l}\text { Santos et al. (2014) } \\
\text { Ensino } \\
\text { Fundamental I } \\
\end{array}$ & $\begin{array}{l}1 \text { professora e } 4 \text { do quarto ano do Ensino } \\
\text { Fundamental I, pertencentes à rede } \\
\text { municipal de Vitória, Espírito Santo }\end{array}$ & $\begin{array}{l}\text { Estudo descritivo, de } \\
\text { abordagem qualitativa, } \\
\text { exploratório e transversal }\end{array}$ \\
\hline $\begin{array}{l}\text { Nascimento (2017) } \\
\text { Ensino } \\
\text { Fundamental I }\end{array}$ & $\begin{array}{l}\text { Professores que atuavam como docentes } \\
\text { na área de Educação Física, em classes do } \\
\text { 60 ao 9o ano }\end{array}$ & $\begin{array}{l}\text { Estudo descritivo, de } \\
\text { abordagem qualitativa, } \\
\text { exploratório e transversal }\end{array}$ \\
\hline
\end{tabular}

Fonte: Elaborado pelos autores.

\section{Resultados da pesquisa com os professores}

A partir da Tabela 1 pode ser observada a percepção dos professores de Educação Física acerca do uso de práticas avaliativas no Ensino Infantil e Fundamental I. Sendo assim, inicialmente, é possível perceber que um pouco mais da metade $(52,2 \%)$ dos professores (as) que lecionam nesses dois níveis de ensino indicaram sempre fazer avaliação do ensinoaprendizagem. Além disso, apenas 56,5\% dos participantes responderam realizar avaliação formativa, pelo menos, frequentemente. Outro dado que merece destaque diz respeito à avaliação diária, em que $47,8 \%$ dos professores afirmam realizar esse ato "sempre". Esse resultado vai ao encontro as orientações de Souza Júnior (2011). 
A. E. C. de Medeiros Filho e K. B. B. de Oliveira e G. A. G. M. Forte e P. S. VERÇOSA E J. A. DE F. PONTES JUNIOR

Tabela 1 - Avaliação do ensino-aprendizagem na Educação Física no Ensino Infantil e Fundamental I.

\begin{tabular}{|c|c|c|c|c|c|}
\hline \multirow{2}{*}{$\begin{array}{c}\text { Variável } \\
\text { Avaliação do ensino- } \\
\text { aprendizagem }\end{array}$} & \multicolumn{4}{|c|}{ Porcentagem (\%) } & \multirow[b]{2}{*}{ Moda $\left(M_{0}\right)$} \\
\hline & Nunca & Às vezes & Frequente & Sempre & \\
\hline $\begin{array}{l}\text { Avaliação de ensino- } \\
\text { aprendizagem }\end{array}$ & 8,7 & 4,3 & 34,8 & 52,2 & Sempre \\
\hline Avaliação diagnóstica ou inicial & 8,7 & 21,7 & 43,5 & 26,1 & Frequente \\
\hline $\begin{array}{l}\text { Avaliação formativa } \\
\text { processual }\end{array}$ & 4,3 & 21,7 & 56,5 & 17,4 & Frequente \\
\hline Avaliação somativa ou final & 8,7 & 13 & 47,8 & 30,4 & Frequente \\
\hline Avaliação anual & 13 & 8,7 & 30,4 & 47,8 & Sempre \\
\hline Avaliação bimestral & 4,3 & 4,3 & 39,1 & 52,2 & Sempre \\
\hline Avaliação diária & 13 & 17,4 & 21,7 & 47,8 & Sempre \\
\hline
\end{tabular}

Fonte: Elaborada pelos autores.

Na Tabela 2 pode ser observado que 4 dos 7 itens sobre avaliação tiveram como moda o nível "sempre" e os outros 3 "frequentemente", indicando que os docentes possuem bons dados de ocorrência de avaliação nesses níveis de ensino. Essas modas pouco variam em relação ao sexo, apresentando apenas resultado bimodal na variável avaliação diagnóstica e avaliação bimestral, sendo o primeiro nos resultados dos professores e no segundo das professoras.

No que concerne aos resultados em relação ao sexo dos participantes, $70 \%$ dos professores realizam sempre avaliações do processo de ensino-aprendizagem, enquanto apenas $38,5 \%$ das professoras realizam sempre este tipo de avaliação. Ainda nessa vertente, a maioria dos professores (70\%) realiza frequentemente mais avaliações formativas ou processuais em comparação às professoras $(46,2 \%)$ (Tabela 2$)$. 
Tabela 2 - Comparação das porcentagens em relação ao sexo.

\begin{tabular}{|c|c|c|c|c|c|}
\hline \multirow{2}{*}{$\begin{array}{c}\text { Variável } \\
\text { Sexo }\end{array}$} & \multicolumn{4}{|c|}{ Porcentagem (\%) } & \multirow{2}{*}{ Moda $\left(M_{0}\right)$} \\
\hline & Nunca & Às vezes & Frequente & Sempre & \\
\hline \multicolumn{5}{|c|}{ Avaliação de ensino-aprendizagem na Educação Física } & \multirow{3}{*}{$\begin{array}{c}\text { Sempre } \\
\text { Bimodal: Sempre } \\
\text { e Frequente }\end{array}$} \\
\hline 1-Masculino & 0 & 0 & 30 & 70 & \\
\hline $2-$ Feminino & 15,4 & 7,7 & 38,5 & 38,5 & \\
\hline \multicolumn{5}{|c|}{ Avaliação diagnóstica ou inicial } & \multirow{3}{*}{$\begin{array}{c}\text { Bimodal: Sempre } \\
\text { e Frequente } \\
\text { Frequente }\end{array}$} \\
\hline 1-Masculino & 0 & 20 & 40 & 40 & \\
\hline 2-Feminino & 15,4 & 23,1 & 46,2 & 15,4 & \\
\hline \multicolumn{6}{|c|}{ Avaliação formativa ou processual } \\
\hline 1-Masculino & 0 & 10 & 70 & 20 & Frequente \\
\hline 2-Feminino & 7,7 & 30,8 & 46,2 & 15,4 & Frequente \\
\hline \multicolumn{6}{|c|}{ Avaliação somativa ou final } \\
\hline 1-Masculino & 10 & 20 & 40 & 30 & Frequente \\
\hline 2 -Feminino & 7,7 & 7,7 & 53,8 & 30,8 & Frequente \\
\hline \multicolumn{6}{|l|}{ Avaliação anual } \\
\hline 1-Masculino & 10 & 10 & 20 & 60 & \multirow{2}{*}{$\begin{array}{c}\text { Sempre } \\
\text { Bimodal: Sempre } \\
\text { e Frequente }\end{array}$} \\
\hline $2-$ Feminino & 15,4 & 7,7 & 38,5 & 38,5 & \\
\hline \multicolumn{5}{|l|}{ Avaliação bimestral } & \multirow{3}{*}{$\begin{array}{c}\text { Sempre } \\
\text { Bimodal: Sempre } \\
\text { e Frequente }\end{array}$} \\
\hline 1-Masculino & 0 & 10 & 30 & 60 & \\
\hline 2 -Feminino & 7,7 & 0 & 46,2 & 46,2 & \\
\hline \multicolumn{6}{|l|}{ Avaliação diária } \\
\hline 1-Masculino & 10 & 20 & 10 & 60 & Sempre \\
\hline $2-$ Feminino & 15,4 & 15,4 & 30,8 & 38,5 & Sempre \\
\hline
\end{tabular}

Fonte: Elaborada pelos autores.

Em relação ao tipo de escola, os resultados apontam que a maioria dos professores de Educação Física $(72,7 \%)$ de instituições particulares realiza sempre avaliação do ensinoaprendizagem e dos professores de escolas públicas, apenas 33,3\%. Nessa perspectiva, somente a metade $(50 \%)$ dos professores de escolas públicas e um pouco mais da metade $(63,6 \%)$ dos professores de escolas particulares realizam frequentemente avaliação formativa ou processual (Tabela 3). 
Tabela 3 - Comparação das porcentagens de avaliações em relação ao tipo de escola.

\begin{tabular}{|c|c|c|c|c|c|}
\hline Variável & & & ntagem (\%) & & M d IM I \\
\hline Sexo & Nunca & Às vezes & Frequente & Sempre & \\
\hline
\end{tabular}

Avaliação de ensino-aprendizagem na Educação Física

\begin{tabular}{|l|c|c|c|c|c|} 
1- Pública & 16,7 & 8,3 & 41,7 & 33,3 & Frequente \\
2- Particular & 0 & 0 & 27,3 & 72,7 & Sempre \\
\hline
\end{tabular}

Avaliação diagnóstica ou inicial

\begin{tabular}{l|c|c|c|c|c} 
1-Pública & 8,3 & 33,3 & 41,7 & 16,7 & Frequente \\
2-Particular & 9,1 & 9,1 & 45,5 & 36,4 & Frequente
\end{tabular}

Avaliação formativa ou processual

\begin{tabular}{|c|c|c|c|c|c|}
\hline 1-Pública & 8,3 & 33,3 & 50 & 8,3 & Frequente \\
\hline 2-Particular & 0 & 9,1 & 63,6 & 27,3 & Frequente \\
\hline
\end{tabular}

Avaliação somativa ou final

\begin{tabular}{l|c|c|c|c|c} 
1-Pública & 8,3 & 16,7 & 58,3 & 16,7 & Frequente \\
2-Particular & 9,1 & 9,1 & 36,4 & 45,5 & Sempre \\
\hline
\end{tabular}

Avaliação anual

\begin{tabular}{|l|c|c|c|c|c|}
\hline 1-Pública & 8,3 & 16,7 & 33,3 & 41,7 & Sempre \\
\hline 2-Particular & 18,2 & 0 & 27,3 & 54,5 & Sempre \\
\hline
\end{tabular}

Avaliação bimestral

\begin{tabular}{|l|c|c|c|c|c|}
\hline 1-Pública & 8,3 & 8,3 & 50 & 33,3 & Frequente \\
2-Particular & 0 & 0 & 27,3 & 72,7 & Sempre \\
\hline
\end{tabular}

Avaliação diária

\begin{tabular}{l|c|c|c|c|c} 
1-Pública & 16,7 & 25 & 16,7 & 41,7 & Sempre \\
2-Particular & 9,1 & 9,1 & 27,3 & 54,5 & Sempre \\
\hline
\end{tabular}

Fonte: Elaborada pelos autores.

Ainda a respeito da avaliação quanto ao tipo de escola, em 3 dos 7 itens analisados as escolas particulares possuem moda superior às escolas públicas e em todos os percentuais em "sempre" foram maiores para esse tipo de escola. Observe-se que o nível de exigência dos docentes das escolas particulares é maior, apontando para necessidade de resposta da qualidade do serviço educacional oferecido. Encontra-se disposta na Tabela 4 a moda por variável, ou seja, por sexo, tipo de escola, bem como no geral. 
Tabela 4 - Moda $\left(M_{0}\right)$ dos totais por variáveis.

\begin{tabular}{|c|c|c|c|c|}
\hline Masculino & Feminino & Escola pública & Escola particular & Geral \\
\hline \multicolumn{5}{|c|}{ Avaliação de ensino-aprendizagem } \\
\hline Sempre & Sempre & Frequente & Sempre & Sempre \\
\hline \multicolumn{5}{|c|}{ Avaliação diagnóstica ou inicial } \\
\hline Bimodal $^{1}$ & Frequente & Frequente & Frequente & Frequente \\
\hline \multicolumn{5}{|c|}{ Avaliação formativa ou processual } \\
\hline Frequente & Frequente & Frequente & Frequente & Frequente \\
\hline \multicolumn{5}{|c|}{ Avaliação somativa ou final } \\
\hline $\begin{array}{c}\text { Frequente } \\
\text { Avaliação anual }\end{array}$ & Frequente & Frequente & Sempre & Frequente \\
\hline Sempre & Sempre & Sempre & Sempre & Sempre \\
\hline \multicolumn{5}{|c|}{ Avaliação bimestral } \\
\hline Sempre & Bimodal $^{1}$ & Frequente & Sempre & Sempre \\
\hline \multicolumn{5}{|l|}{ Avaliação diária } \\
\hline Sempre & Sempre & Sempre & Sempre & Sempre \\
\hline \multicolumn{5}{|c|}{ Moda dos totais das variáveis } \\
\hline Sempre & Frequente & Frequente & Sempre & Sempre \\
\hline
\end{tabular}

${ }^{1}$ Bimodal para Sempre e Frequente

Fonte: Próprios autores.

É oportuno destacar que, em apenas "avaliação diagnóstica ou inicial" e a "avaliação formativa ou processual" a moda (Frequente) é a mesma entre as escolas públicas e particulares. Todas as outras, assim como já foi descrito no parágrafo anterior, mostra uma moda de maior frequência (Sempre) para as escolas particulares, o que leva a inferir que, de certa forma, que há um maior comprometimento e utilização das práticas avaliativas nas aulas de Educação Física em escolas deste tipo.

\section{Discussão}

Considera-se que os objetivos propostos no estudo foram atingidos, uma vez que os resultados mostram evidências acerca da escassez de produções científicas, críticas aos processos metodológicos e técnicos acometidos pelo professores e o fato de a avaliação formativa ser, predominantemente, realizada pelos professores de escolas particulares. Quanto às críticas levantadas na revisão integrativa, elas realçam a necessidade de utilizar diferentes instrumentos de coleta de informações na Educação Física escolar. Nessa perspectiva, Savi et al. (2016) abordam que se faz necessário que o professor, ao avaliar na 
dimensão atitudinal, faça a utilização de indicadores além da participação, ou seja, que contemple a relação professor-aluno, trabalhos a serem realizados coletivamente e/ou individuais, dentre outros. Alertam ainda para a não exclusão dos alunos menos habilidosos em detrimento dos considerados habilidosos.

O apontamento de Wagner e Francine (2013) também merece destaque uma vez que relata que o processo avaliativo não deve ser classificatório e nem excludente, como também não deve se limitar apenas em atribuir nota ou conceito. Assim, verificar ou aferir o desempenho dos alunos é apenas uma etapa do processo avaliativo, em que, por sua vez, deveria refletir sobre as informações coletadas para que seja possível determinar ações que possibilitem mudanças no contexto investigado (VIANNA; 2000; PONTES JUNIOR, 2014).

Quanto aos critérios a serem considerados na avaliação, Santos et al. (2014) relatam a importância de deixá-los explícitos para os educandos. Corroborando, Magalhães Júnior (2015) ressalta que o professor, ao definir o que deseja avaliar, deve construir os critérios a serem considerados e na sequência apresentar aos avaliados.

Todos os pontos discutidos acima devem ser considerados pelos professores de Educação Física das séries iniciais da Educação Básica, uma vez que as particularidades existentes nesta disciplina deixam o processo avaliativo mais complexo. Dessa forma, mais produções científicas acerca dessa temática podem possibilitar reflexões e a ampliação dos saberes dos professores de Educação Física em relação à prática avaliativa nos níveis de ensino aqui discutidos.

A partir dos resultados apresentados sobre as práticas avaliativas no Ensino Infantil e Fundamental I na percepção dos professores de Educação Física, de acordo com o sexo e tipo de escola, é possível notar que a avaliação do processo de ensino-aprendizagem é aderida pelos professores participantes deste estudo, principalmente, por aqueles que lecionam em escolas particulares. Nesse sentido, surgem alguns questionamentos os quais merecem destaque: o que justifica os professores de escolas particulares adotarem mais avaliações em sua prática-pedagógica? Seria para detectar possíveis equívocos e corrigi-los ao longo do processo de ensino-aprendizagem? Ou seria maior pressão para apresentar resultados aos pais ou responsáveis dos educandos por meio de desempenho emitido em conceituação 
numérica? Esse último se apresenta como uma das características comuns das unidades de ensino particulares (SEVERINO; ADRIANO, 2015).

Tais questionamentos crescem quando se trata de outros componentes curriculares como o de Língua Portuguesa e Matemática. As avaliações externas, como no caso a Avaliação Nacional da Educação Básica (ANEB) requer dos alunos de $5^{\circ}$ e $9^{\circ}$ ano do Ensino Fundamental, bem como do $3^{\circ}$ ano do Ensino Médio, conhecimentos mínimos necessários nesses dois componentes curriculares (BELTRÃO, 2014).

Nessa perspectiva, as políticas de responsabilização nascem, também, quando as avaliações sejam elas internas ou externas, possibilitam aos gestores e educadores a utilização dos resultados para tomar decisões na intenção de proporcionar um serviço educacional de qualidade. No entanto, a utilização dos dados oriundos das avaliações nem sempre são utilizados pelos tomadores de decisão presentes no contexto educacional (MANDINACH; GRUMMER, 2013).

Diante desse contexto, quando as avaliações externas estão associadas à noção de accountability e responsabilização podem influenciar de forma negativa nos autênticos objetivos da educação, como a desqualificação da sua função social. Exemplo disso é o uso excessivo de avaliações durante o ano letivo quando se tem a intenção de preparar, no sentido técnico, os alunos para as avaliações externas (SILVA; CARVALHO, 2014).

Noutra vertente, é possível planejar e idealizar avaliações formativas ou processuais desde os anos iniciais da Educação Básica. Além disso, são necessários objetivos que possibilitem a restruturação das práticas docentes e, consequentemente, melhoria da aprendizagem dos alunos (NEVES; MORO, 2013; MACPHAIL; MURPHY, 2017).

Em consonância, Souza Júnior (2011) defende que a avaliação no componente Educação Física não deve ocorrer somente no final das aulas, em espécie de retomada ou revisão do que foi trabalhado em sala de aula. Pelo contrário, é preciso que o ato de avaliar aconteça no início e percorra todo o tempo de aula (processo formativo). A utilização de diferentes ferramentas, como, por exemplo, relatórios, fichários, observação sistematizada, autoavaliação, portfólio, dentre outras, pode contribuir nas práticas avaliativas. 
A. E. C. De Medeiros Filho e K. B. B. de Oliveira e G. A. G. M. Forte e P. S. VERÇOSA E J. A. DE F. PONTES JUNIOR

Independente da vinculação administrativa das escolas e nível de ensino, a avaliação precisa ocorrer perante um processo contínuo. Nessa perspectiva, na Educação Física escolar, em especial no Ensino Infantil é indispensável um acompanhamento efetivo do professor próximo ao aluno (SILVA; PIRES; PEREIRA, 2013).

As produções científicas acerca da avaliação da aprendizagem nas aulas de Educação Física muito se fundamentam pela avaliação formativa e somativa. No entanto, outras abordagens podem ser mencionadas a partir da revisão de literatura internacional produzida por López-Pastor et al. (2012). Elas foram categorizadas em seis: avaliação alternativa, avaliação autêntica, avaliação para aprendizagem, avaliação formativa, avaliação da aprendizagem e avaliação integrada.

Diante do exposto, considera-se a importância e a complexidade das práticas avaliativas nas aulas de Educação Física escolar, caracterizando-as como um processo problemático que dificulta, mas não anula as possibilidades de os professores empregarem boas práticas avaliativas (HAY; PENNEY, 2013; LORENTE-CATALÁN; KIRK, 2015).

Desse modo, a referida temática deve, entre outros meios, ser discutida na literatura científica, em eventos e, indispensavelmente, na formação inicial de professores. Por fim, as discussões não devem se restringir às concepções e procedimentos avaliativos, mas também quanto ao papel que elas podem afetar no grau de legitimidade da Educação Física na escola e em sua função social.

\section{Considerações Finais}

A partir dos resultados e as discussões levantadas neste estudo, evidenciou-se que as práticas avaliativas fazem parte do ato pedagógico dos professores de Educação Física que atuam no Ensino Infantil e Fundamental I, em especial os que atuam em escolas particulares. No entanto, foram identificadas algumas necessidades de melhoria que precisam ser repensadas as quais, parte delas, são: escassez de estudos sobre a avaliação em Educação Física no Ensino Infantil I Fundamental I; as produções científicas acerca das práticas avaliativas na Educação Física no Ensino Infantil e Fundamental I têm demonstrado críticas aos processos metodológicos e técnicos acometidos pelo professores (as); a realização de 
A. E. C. De Medeiros Filho e K. B. B. de Oliveira e G. A. G. M. Forte e P. S. VERÇOSA E J. A. DE F. PONTES JUNIOR

avaliação formativa ou processual é mais frequente por parte dos professores (as) de escolas particulares.

Contudo, mediante o exposto, espera-se contribuir na discussão sobre as práticas avaliativas realizadas pelos professores de Educação Física que atuam no Ensino Infantil e Fundamental I e, sobretudo, possibilitar intervenções de atores políticos e demais interessados para o aprimoramento da atuação dos professores quanto às práticas avaliativas. Ocorrendo isso, o professor é capaz de propor uma avaliação mais justa das aprendizagens dos alunos. Adicionalmente, sugerem-se novos estudos que contemplem algumas limitações encontradas, como, por exemplo, o número reduzido de bases eletrônicas para busca de produções científicas tanto no âmbito nacional, quanto internacional, bem como a ampliação no número de professores e contextos para compor a amostra.

\section{Referências}

BAUER, A.; GATTI, B.; TAVARES, M. (Orgs.). Vinte e cinco anos de avaliação de sistemas educacionais no Brasil: Origem e pressupostos. Florianópolis: Insular, 2013.

BELTRÃO, J. A. A educação física na escola do vestibular: as possíveis implicações do ENEM. Movimento - Revista de Educação Física da UFRGS, v. 20, n. 2, p. 819-840, 2014. Disponível em: <http://www.seer.ufrgs.br/index.php/Movimento/article/view/41801/28928>. Acesso em: 14 jul. 2017.

BERTOLIN, J. C. G.; MARCON, T. O (des) entendimento de qualidade na educação superior brasileira - Das quimeras do provão e do ENADE à realidade do capital cultural dos estudantes. Revista de Avaliação da Educação Superior, v. 20, n. 1, p. 105-122, 2015. Doi: http://dx.doi.org/10.590/S1414-40772015000100008.

BRASIL. Ministério da Educação e Cultura. Parâmetros Curriculares Nacionais: Educação Física. Brasília: MEC/SEF, 1997. Disponível em: <http://portal.mec.gov.br/seb/arquivos/pdf/livro03.pdf>. Acesso em: 25 ago. 2017.

BRASIL. Ministério da Educação e Cultura. Parâmetros Curriculares Nacionais: Educação Física. Brasília: MEC/SEF, 1998. Disponível em: <http://portal.mec.gov.br/seb/arquivos/pdf/fisica.pdf>. Acesso em: 7 nov. 2017.

BRASIL. Ministério da Educação. Base Nacional Comum Curricular. Proposta preliminar. Terceira versão revista. Brasília: MEC, 2017. Disponível em:

$<$ http://basenacionalcomum.mec.gov.br/images/BNCC_publicacao.pdf >. Acesso em: 24 out. 2017.

BRASIL. Ministério da Saúde. Resolução no 510, de 07 de abril de 2016. Disponível em: <http://conselho.saude.gov.br/resolucoes/2016/Reso510.pdf>. Acesso em: 22 abr. 2017. 
CALLADO, C. V.; ARANDA, A. F.; LÓPEZ-PASTOR, V. M. Aprendizaje cooperativo en Educación Física. Movimento. Porto Alegre, v. 20, n. 1, p. 239-259, jan/mar. 2014. Disponível em: <http://dx.doi.org/10.22456/1982-8918.40518>. Acesso em: 15 nov. 2017.

CALDERÓN, A. I.; BORGES, R. M. Avaliação Educacional: Uma abordagem à luz das revistas científicas brasileiras. Revista Iberoamericana de Evaluación Educativa, v. 6, n. 1, p. 167183, 2013. Disponível em: <http://www.red-redial.net/referencia-bibliografica-68466.html>. Acesso em: 1 de nov. 2017.

COLASANTO, C. A. Avaliação na Educação Infantil: a participação da criança. 2014. 198 f. Tese (Doutorado em Educação) - Pontifícia Universidade Católica de São Paulo, São Paulo, 2014. Disponível em: <https://sapientia.pucsp.br/handle/handle/9802?locale=en>. Acesso em: 10 out. 2017.

FREITAS, L. C. et al. Avaliação educacional: caminhando pela contramão. Petrópolis: Vozes, 2017.

GALVAN, J. L. Writing Literature Reviews: A Guide for Students of the Social and Behavioral Sciences. 7. ed. Glendale, CA: Pyrczak Pub., 2017.

GALVÃO, T. F.; PANSANI, T. S. A.; HARRAD, D. Principais itens para relatar Revisões sistemáticas e Meta-análises: A recomendação PRISMA. Epidemiologia e Serviços de Saúde, v. 24, p. 335-342, 2015.

LÓPEZ-PASTOR, V. et al. Alternative assessment in physical education: a review of international literature. Sport Education and Society, v. 18, n. 1, p. 57-76, 2012.

LORENTE-CATALÁN, E.; KIRK, D. Student teachers' understanding and application of assessment for learning during a physical education teacher education course. European Physical Education Review, v. 22, n. 1, p. 65-81, 2015.

MACPHAIL, A.; MURPHY, F. Too much freedom and autonomy in the enactment of assessment? Assessment in physical education in Ireland. Irish Educational Studies, v. 3, p. 237-252, 2017.

MAGALHÃES JÚNIOR, A. G. Avaliação na Educação a Distância. Fortaleza: EdUECE, 2015. Disponível em: http://www.sate.uece.br/moodle2/mod/resource/view.php?id=53968. Acesso em: 07 jul. 2018.

MANDINACH, E.; GRUMMER, E. A Systemic View of Implementing Data Literacy in Educator Preparation. Educational Researcher, v. 42, p. 30-37, jan./fev. 2013. Disponível em: <http://edr.sagepub.com/content/42/1/30.short>. Acesso em: 16 nov. 2014.

MATSUMOTO, M. H. Avaliação e educação física escolar: práticas cotidianas de professores da rede pública do Estado de São Paulo. Tese (Doutorado em Educação) - Universidade Estadual de Campinas, Campinas, 2014. Disponível em: <http://repositorio.unicamp.br/bitstream/REPOSIP/253937/1/Matsumoto_MarinaHisa_D.p df>. Acesso em: 20 out. 2017.

NASCIMENTO, K. C. C. Avaliação da aprendizagem na educação física escolar na zona rural no município de Formosa: realidade e contradições. 2017. 257 f. Dissertação (Mestrado em 
Ensino) - Universidade Federal de Goiás, Goiânia, 2017. Disponível em: <https://repositorio.bc.ufg.br/tede/handle/tede/7778>. Acesso em: 20 out. 2017.

NEVES, V. F. A.; MORO, C. Avaliação na educação infantil: um debate necessário. Estudo em Avaliação Educacional, v. 24, n. 55, p. 272-302, 2013.

NOVAES, R. C.; FERREIRA, M. S.; MELLO, J. G. As dimensões da avaliação na Educação Física escolar: uma análise de produção de conhecimento. Motrivivência, v. 26, n. 42, p. 146-160, 2014.

PONTES JUNIOR, J. A. F. Avaliação do ensino-aprendizagem nas aulas de Educação Física nas escolas públicas e particulares de Fortaleza-Ce. Dissertação (Mestrado). Universidade Federal do Ceará, Faculdade de Educação, Programa de Pós-Graduação em Educação Brasileira, Fortaleza-CE, 2012. Disponível em:

<http://www.repositorio.ufc.br/bitstream/riufc/3116/1/2012_Dis_JafPontes\%20Junior.pdf>. Acesso em: 01 de jun. 2017.

PONTES JUNIOR, J. A. F. Matriz ACEF9: matriz de referência para avaliação cognitiva em larga escala dos conteúdos da educação física no ensino fundamental (9a ano). 2014. 128f. Tese (Doutorado em Educação) - Universidade Federal do Ceará, 2014. Disponível em: <http://www.repositorio.ufc.br/handle/riufc/10477\&gt;>. Acesso em: 3 de out. 2017.

SANTOS, W. et al. Avaliação na educação física escolar: construindo possibilidades para a atuação profissional. Educação em Revista Belo Horizonte, v. 30, n. 04, p. 153-179, 2014. Disponível em: <http://www.scielo.br/pdf/edur/v30n4/08.pdf>. Acesso em: 25 out. 2017.

SAVI, E. et al. Avaliação atitudinal da educação física na escola. REMAS-Revista Educação, Meio Ambiente e Saúde, v. 6, n. 4, p. 110-112, 2016. Disponível em: <http://faculdadedofuturo.edu.br/revista1/index.php/remas/article/view/102>.

SEVERINO, C. D.; ADRIANO, L. G. Pontos divergentes da Educação Física em Escolas Públicas e Privadas: a visão de professores do Ensino Superior. Cadernos UniFOA, n. 28, p. 91-105, ago. 2015. Disponível em: <http://web.unifoa.edu.br/cadernos/edicao/28/91-105.pdf>. Acesso em: 16 nov. 2017.

SILVA, M. R.; PIRES, G. L.; PEREIRA, R. S. O corpo-infância nos "exercícios de ser criança" nas aulas de Educação Física na Educação infantil e nos anos iniciais do ensino fundamental. Motrivivência, v. 27, n. 45, p. 6-12, 2015. Disponível em: <https://periodicos.ufsc.br/index.php/motrivivencia/article/view/21758042.2015v27n45p6/ 30213>. Acesso em: 15 nov. 2017.

SILVA, V. G.; CARVALHO, C. P. Usos e efeitos das avaliações externas como objeto de pesquisa. Estudos em Avaliação Educacional, v. 25, n. 59, p. 12-21, 2014.

SOUZA JÚNIOR, M. Práticas avaliativas e aprendizagens significativas em educação física: trajetória, orientações legais e implicações pedagógicas. In: DIAS, A. C. et al. (Orgs.), Prática pedagógica e formação profissional na educação física: reencontros com caminhos interdisciplinares. 2. ed. Recife: EDUPE, 2011. p. 151-173. 
THOMAS, J. R.; NELSON, J. K.; SILVERMAN, S. J. Métodos de pesquisa em atividade física. 6. ed. Porto Alegre: Artmed, 2012.

VIANNA, H. M. Avaliação do rendimento escolar e a interação professor/aluno. Estudos em Avaliação Educacional, n. 7, p. 89-94, 1993.

VIANNA, H. M. Avaliação educacional: teoria, planejamento e modelos. São Paulo: IBRASA, 2000.

WAGNER, S.; FRANCINE, L. M. Avaliação na educação física escolar: singularidades e diferenciações de um componente curricular. Revista Brasileira de Ciências do Esporte, v. 35, n. 4, p. 883-896, 2013. Disponível em:

<http://www.redalyc.org/articulo.oa?id=40133857>. Acesso em: 20 out. 2017.

Recebido em: 25/11/2017

Aprovado em: 07/07/2018 